\title{
Enhancing Students' Achievement in Chemistry through the Piagetian Model: The Learning Cycle
}

\author{
Felicia Opara ${ }^{1}$, Peter Waswa ${ }^{2}$ \\ University of Anambra, Nigeria ${ }^{1}$, University of Eldoret, Kenya ${ }^{2}$
}

\begin{abstract}
The study sought to investigate the efficacy of the learning cycle on students ' achievement in Chemistry. Two research questions and two hypotheses guided the study. It was hypothesized that the mean achievement scores of students taught chemistry using the learning cycle and those taught through traditional approaches would not differ significantly. Piaget's theory on mental functioning formed the theoretical framework of the study. 430 students in Kenya participated in the study. Pretest posttest control group was the study design. Cronbach alpha used to test the reliability of the instruments (Pretest and posttest) gave 0.76 and 0.72 respectively. Data was analyzed using mean and standard deviation for the research questions; ANOVA and t-test for hypotheses showed that the learning cycle enhanced the achievement of students in the experimental group. The mean achievement scores showed that the boys performed better than the girls while independent t- test and ANOVA showed the difference between the mean scores as statistically insignificant.
\end{abstract}

\section{Introduction}

The critical role of chemistry in daily life, in industry and society is limitless. Many of our day-toactivities revolve around chemistry. Chemistry is everywhere; chemistry is life; chemistry is the oracle of modern science. Despite the key role of chemistry as the central science that forms the basic foundation to many disciplines and in improving the quality of life, the performance of Kenya secondary students in the subject has for many years remained a matter of a serious concern. The graph below shows that the mean achievement scores of students in chemistry from 2005 to 2010 were $26.99,24.78,25.17,22.50$, 18.99 and 24.71 respectively.

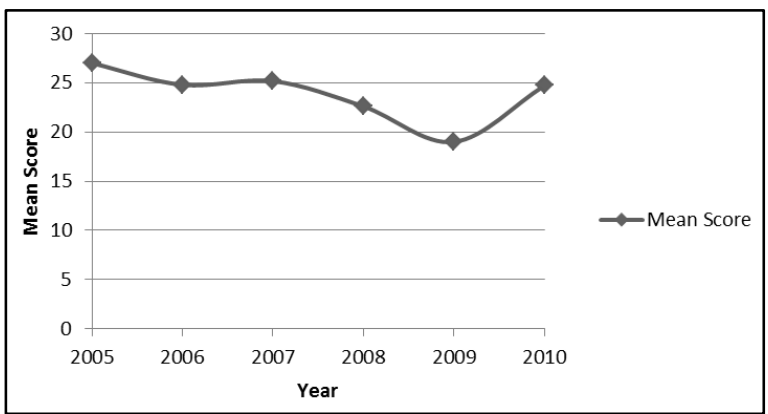

Figure 1. Mean scores of students in Chemistry (2005 - 2010)

This has attracted concern of many stakeholders across the country. For a candidate to qualify for entry into the University or College, s/he must produce a pass at credit level of $\mathrm{C}+$ or $\mathrm{C}$ respectively at the Kenya Certificate Secondary Education (KCSE) in two science subjects selected from Physics, Chemistry and Biology.

However, record of analysis of students' results in Physics, Chemistry and Biology as shown by [9] for a number of years has revealed dismal failure, with Chemistry being the poorest as shown in the chart below.

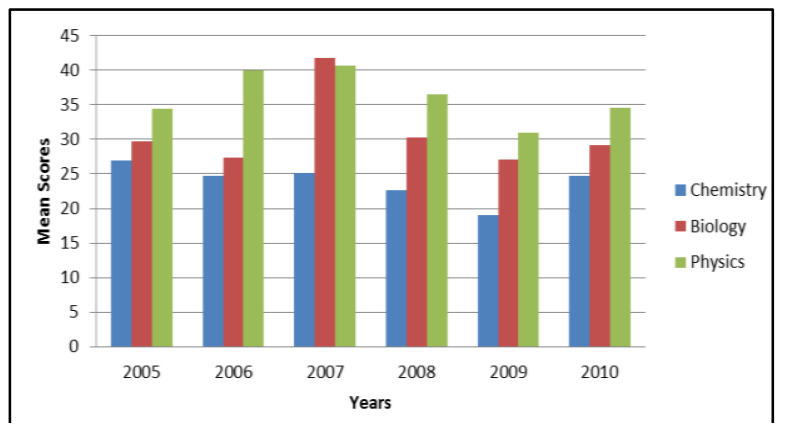

Figure 2. Performance of students in Chemistry relative to Biology and Physics (2005 - 2010)

The annual mean achievement scores also showed a gender disparity between male and female students as boys outperformed the girls in chemistry. 


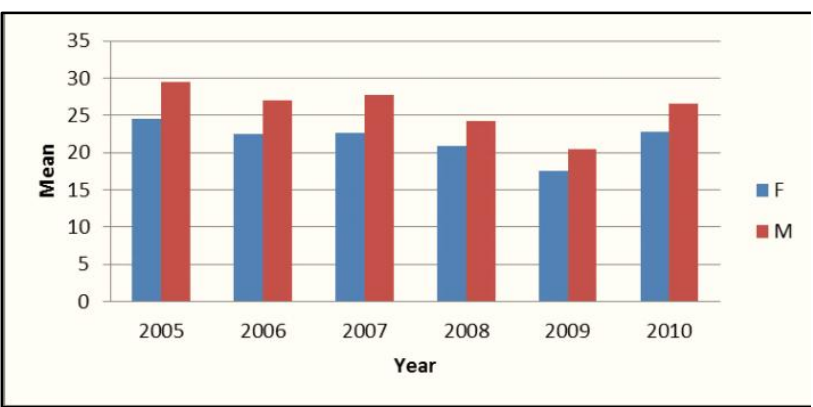

Figure 3. Mean scores of students' performance in

Chemistry in KCSE by gender (2005 - 2010)

Efforts made through research to discover the causal factors of the persistent failure disclosed that secondary school chemistry teachers mainly adopt the lecture method in the teaching and learning of chemistry [17]. According to Lovat [10] "teaching is not an incidental craft to follow naturally from mastery of subject content, but a highly complex blend of theoretical understanding and practical skill". Thus, Eze opined that the incompetence of the science teacher stems from poor teacher preparation [7]. In 1998, Strengthening Mathematics and Sciences in Secondary School Education (SMASSE) project was mounted. SMASSE was organized by the Ministry of Education Science and Technology (MOEST) in collaboration with the Government of Japan International Cooperation Agency (JICA). One of the aims of the project was to help teachers improve their content knowledge and teaching methodology to equip them with the competence of adopting strategies of meaningful and deep learning.

Meaningful learning occurs when learners comprehend concepts and are able to connect them with previous knowledge [2]. When students learn chemistry meaningfully, their ability to reflect on their own learning and make adjustments accordingly fosters deeper learning. Deeper learning is the key strategy through which students find meaning and understanding from course material and experiences [19] which in turn may result to competence of knowledge transfer to other domains and how to apply the knowledge in answering questions and resolving problems [12]. This is referred to as 21st century competencies that are precluded in teaching methods that promote memorization of procedures and recall of facts and principles. In such traditional approaches where the teacher transmits knowledge to passive learners who are seen as "empty vessels" into which knowledge is to be poured, little learning takes place [18].

Research has shown that students do not enter the classroom as a "blank slate" [15]. Learners construct knowledge by making connections between new information and their existing conceptual network because "learning is an active process of knowledge construction, the making of connections between existing network of knowledge" [13]. According to Bybee, students' prior conceptions, ideas and experiences which they carry to the classroom influence the way they learn new concepts and skills [3]. Hence, it is important that they are actively engaged in the learning process and that they are challenged to reflect on their own learning besides being able to link their prior knowledge to new knowledge.

Emphasis on traditional approaches and coverage of content mapped out in the school syllabus and scheme of work for the four years of secondary education (Kenya runs 8-3-3-4 system on education) have resulted to students learning chemistry without conceptual understanding. Recent studies done in Kenya such as [5] and [16] confirm that teachers tend to rush through the scheme of work to enable them cover the topics in the curriculum within the given period. The learning cycle is a model which builds on students' prior knowledge but also shifts emphasis from the instructor to the leaner and the active role played by the leaner in the learning process. It is a pragmatic approach derived from [14] theory of intellectual development especially the aspect on mental functioning. More recent studies such as [3] observed that the 5E Model of the learning is also based on the educational philosophy and psychology of Johann Herbart. According to [3], the need to build new knowledge, based upon prior knowledge and to connect new and old information was the premise of Herbart's pedagogical model.

The stages of the learning cycle correspond to Piaget's assimilation, accommodation and organization. Assimilation is the "active process of making meaning out of experience" [8]. In assimilation, individuals interact with data in the environment to be processed in the mental structures which can change during the learning process to result in accommodation. However, when the meaning of some data is uncertain to the individual cognitive dissonance or disequilibrium can occur. Disequilibrium has to do with the confusion or perplexity arising in students' mental structure when "the explanation used for an earlier experience just does not seem to fit the new experience" [11]. Nonetheless, one advantage of cognitive conflict or disequilibrium is that it can arouse the curiosity of students to want to learn more. Thus, the desired equilibrium may occur during the changing of thought processes or of one's thinking. When this happens the individual is said to accommodate!

Through assimilation and accommodation students gain proper awareness of the learning 
process and they are able to internalize or even attain deeper learning [1]. The learning cycle incorporates the principles of social constructivism which views learning as an active social process where leaners share ideas and interact in groups to build their understanding together. During this process, developmental changes may occur in leaners' construction of knowledge through an interplay of assimilation and accommodation. The phases of the learning cycle provide opportunity for learners to assimilate information through inquiry process, collaboration in groups and exploration of the learning environment and materials. The extent of accommodation and assimilation are expressed or assessed in the organization process at the evaluation phase of the learning cycle. Thus, the phases of the learning cycle ropes in Piaget's assimilation, accommodation and organization. From the forgoing, four major elements identified by Piaget which should not be overlooked when adopting the learning cycle for teaching chemistry, are maturation, experience, social communication and equilibration. (i) Maturation demands that students participating in the learning process are both biologically and physically mature to be able to carry out the required activities in the laboratory and to explore their learning environment. (ii) By experience, it means that students possess the ability to recall previous knowledge and draw from experience with concrete objects in the laboratory or local environment. It also entails that students can apply their mathematical knowledge to deal with problems on proportionality in chemistry example, the mole concept. (iii) Social communication stems from social constructivism which calls for students' capability to communicate information and effectively interact with themselves and the teacher. It also requires students to be able record to experimental data. (iv) Equilibration entails that students have the capacity to deal with information after grappling with cognitive conflict experienced during brainstorming.

Bybee et al. [4] accredited the 5E learning cycle as an effective model that is based on proven education theories with evidence-based research that supports its use in the classroom; while other studies such as Ergin et al. have shown its significance in enhancing content achievement, retention gains and understanding [6]. Despite the several research evidence in favor of the learning cycle, there is as yet little or no study in Kenya to examine how it will impact on students' achievement in chemistry irrespective of the decrying persistent failure in the subject.

\section{Research questions}

(1) What are the mean achievement scores in chemistry tests of secondary school students taught some selected chemistry topics through the learning cycle and those taught using traditional methods?

(2) What is the effect of gender on mean achievement scores in chemistry tests of secondary school students taught selected chemistry topics through the learning cycle and those taught using traditional methods.

\section{Research hypotheses}

$\mathrm{Ho}_{1}$ The mean achievement scores of students taught selected chemistry topics through the learning cycle and those taught by traditional methods do not differ significantly.

$\mathrm{Ho}_{2}$ There is no significant effect of gender on students mean achievement scores in pre-test and post-test chemistry tests.

\subsection{Population}

The population comprised form II Secondary School Students offering chemistry in Bureti district secondary schools, Kenya

\subsection{Method}

Design of the study: The study was a quasiexperimental pretest-posttest control group design.

\subsection{Sampling Technique}

The sample for study was made up 430 form II chemistry students from 3 male only and 3 female only schools in Bureti district. Kenya. Stratified random sampling was used to select schools from the district that had mean scores below 22.50 in the national examinations in 2008, 2009 and 2010. Purposive sampling was used to select only boarding schools that have two streams offering chemistry from the total of nineteen single sex schools comprising 12 female-only and 7 male -only schools in the district. Therefore, twelve intact classroom groups were randomly assigned to treatment and control groups. Treatment and control groups were randomly assigned to different classes in the same schools to ensure that environmental conditions were the same. The treatment group which was exposed to the learning cycle comprised 215 subjects (112 female and 103 male). The control group which was 
exposed to traditional methods comprised 215 (101 male and 114 female). Bureti district also has 28 mixed/coeducational schools (16 boarding and 12 day). However, some of the schools were single streams and school type as a variable was not considered in this study.

\subsection{Instrument}

Instrument used was made up ten pre-test questions based on mole concept, periodic table, and chemical equations. The posttest also comprised ten restructured questions on the same topics. To determine the reliability of the instrument a pilot study was carried using 98 form II Chemistry students from Bomet district. Cronbach alpha pretest score was 0.76 while post-test score was 0.72 .

3.4.1. Instructional Procedure. The mole concept was one of the topics identified as difficult for students by SMASSE project, hence its significance in this study. The control group was taught using traditional methods of lecture and teacher demonstration. (Given below are parts of sample lessons).

Instructional procedure: Traditional Method Instructional materials: $\mathrm{NaCl}, \mathrm{CaC} 03$, water, conical flasks, measuring cylinder, weighing balance, Periodic Table chart, crate of eggs, oranges

Set induction: Teacher uses dozen of eggs, oranges, to show that the mole can be represented in numbers in terms of measurement. Teacher asks students to count the number of eggs in the crate and the oranges. S/he further asks them whether they can count the sand particles on the ground.

Content Development.

Stage 1. Teacher's Activities: Teacher shows students atomic masses of elements in Periodic Table. S/he explains that particles of element cannot be counted but can be represented in grams. Each element measured in grams $=1$ mole $=\mathrm{Av} \mathrm{No}=6.023$ $\mathrm{x} 1023$.

Stage 2. Teacher's Activities: Teacher defines the term mole. S/he demonstrates to the students how to calculate the molar mass of compounds; then how to measure 1 mole of $\mathrm{NaCl}, \mathrm{CaC03}$. Teacher asks students to weigh $1 / 4$ of same substances given the value in mole and Avogadro number.

Students' activity: Students measure $1 / 4$ of 1 mole of $\mathrm{NaCl}, \mathrm{CaC03}$ using the weighing balance.

Stage 3. Teacher's Activities: Teacher measures 1000 $\mathrm{cm} 3,500 \mathrm{~cm} 3,250 \mathrm{~cm} 3$ of solutions of $\mathrm{NaCl}$, $\mathrm{CaC03}$; then relates mole to volume; s/he then defines the mole, molar mass; explains the conversion of mole to mass to volume; defines molar solution, standard solution.

Students' activity: Students carry out the same demonstration as directed by the teacher. They ask questions and answer teacher's questions.

Stage 4. Teacher's Activities: Teacher prepares $0.05 \mathrm{MHCl}, 1 \mathrm{MKOH}$. He/she demonstrates the difference between molar and standard solution. S/he writes on the chalk board the equation for the reaction between $\mathrm{HCl}$ and $\mathrm{KOH}$ and explains the concept of mole ratio. She gives more examples of how mole ratio is determined in an equation. Concept of concentration is explained and the formula written for the students on the chalk board.

Students' activity: Students observe listen and answer teacher's questions

Stage 5: Evaluation Teacher assesses students by giving them the following assignment: (1) Define the (i) the mole (ii) molar mass (2) Distinguish between molar solution and standard solution (3) Balance the equation of reaction between Sulphuric acid and Potassium Hydroxide.

Strategies applied in this approach are: Lecturing and Demonstration. Students activities are minimal, critical thinking and social interaction in groups are lacking. 
Phase 1a: Questions relating to learners environment were posed by the teacher. You are going to a party and you have been asked to help out by preparing chapatti for 20 people. The recipe given is as follows: $4 \mathrm{~kg}$ of flour. 1 litre of warm water and 0.1 litre of oil

i. What information does the recipe provide?

ii. What is the ratio of substances used in the recipe?

iii. Convert the amount of flour used in grams?

iv. Convert litre of water and oil to $\mathrm{cm}^{3}$.
You are supplied with substances placed on the bench tables arranged according to your working groups.

Observe the specimen bottles

Identify each one from the labels and copy down the names of the substances on the specimen bottles.

Identify the substances in terms of colour and smell.

Write down the formula of each substance (students had learnt how to write formula in form 1).

Deduce the number of atoms in each substance.

Write down each element and find its position in the periodic table; show the metals and the non-metals.

Write down the atomic number and atomic mace of arsh olement

The concept: The mole, conversion of mole to mass, mass to mole, and volume, molar solution, standard solution, mole ratio; Avogadro number; the periodic table and equations are discussed among students. Teacher continued to make open suggestions, providing models where necessary. S/he may show sample of summary of the mole concept using the concept map and ask each group to design similar maps on the topics or choose alternative designs of their $n \times m$

The concept maps/mind maps or diagrams which the students drew and the dexterity with which they deduced formula, balanced and interpreted equations helped the students and the teacher to assess the extent students understood the concepts. Misconceptions were clarified by the teacher as s/he closely supervised students in their discussion groups. Students' recorded work (individual and group) were also examined by the teacher and adequately scored.

Copyright @ 2013 , Infonomics Society

Figure 4. The Learning Cycle: (Instructional procedure: graphical representation)
Phase 1b: If grains of rice are weighed on a kitchen balance and corresponding masses of grains are given as:

Number of grains of rice Corresponding mass

$\begin{array}{ll}200 & 5.0 \mathrm{~g} \\ 400 & 10.0 \mathrm{~g} \\ 800 & 15.0 \mathrm{~g}\end{array}$

i. What quantity of grains will weigh $2.5 \mathrm{~g}$ ?

ii. What is the ratio of grains of rice to mass?

iii. Assuming 200 grains is equivalent to 1 mole of rice, how many moles will 400 grains and 800 grains be?

iv. If you were to receive one Kenya shilling (Ksh) per second, how long will it take to accumulate Kshs. 1 million? Assuming there are $6.03 \times 10^{23}$ particles inside 1Kenya shilling where $6.02 \times 10^{23}$ is equal to (a term called mole), how many shillings are equal to 1 mole; 2 moles; 3 moles.

Phase 1 Engagement

Applying the knowledge you had in form 1 on particles of an atom, show the number of protons, electrons and neutrons in each element

If $\mathrm{He}$ is expressed as 1 mole $\mathrm{He}$, express $2 \mathrm{NaCl}$, $\mathrm{Mg}, \mathrm{Ca}(\mathrm{OH})_{2}$ in moles. Do the same for the substances you listed in (iv)

Express $\mathrm{NaCl}$ in ionic form and show number of moles of ions for $\mathrm{Na}$ and $\mathrm{Cl}$ from the ionic formula.

Do the same for the substances you listed in IV above.

If 1 mole of $\mathrm{NaCl}$ is calculated by adding together the atomic mass of sodium and chlorine, calculate the mass of 1 mole of $\mathrm{Na}_{2} \mathrm{CO}_{3}, \mathrm{NaOH}, \mathrm{H}_{2} \mathrm{SO}_{4}, \mathrm{Ca}(\mathrm{OH})_{2}$.

Now (B) measure $1000 \mathrm{~cm}^{3}, 250 \mathrm{~cm}^{3}, 500 \mathrm{~cm}^{3}$ of water using volumetric flask

Measure 0.5 mole $\mathrm{Ca}(\mathrm{OH})_{2}$, put the substance into a beaker, put some water and stir, pour into $1000 \mathrm{~cm}^{3}$ volumetric flask and top water to exactly $1000 \mathrm{~cm}^{3}$, shake.

What was the mass of $0.5 \mathrm{M} \mathrm{Ca}(\mathrm{OH})_{2}$ that you

The activities in the previous stage would be extended if the students identified the relationships in the mole and are able to extend the knowledge gained so far to a general formula which may guide them in further calculations.

$\mathrm{V}_{1} \mathrm{~cm}^{3}$ of $\mathrm{M}_{1} \mathrm{HCl}$ solution reacted with $\mathrm{V}_{2} \mathrm{~cm}^{3}$ of $\mathrm{M}_{2} \mathrm{KOH}$ solution.

In the titration, $\frac{V_{1} M_{1}}{1000}=$ moles of $\mathrm{HCl}$ reacted with $\frac{V_{2} M_{2}}{1000}=$ moles of $\mathrm{KOH}$

What is the ratio of volume to mole of $\mathrm{HCl}$ and $\mathrm{KOH}$ in the equation? Deduce (i) the formula for the conversion of mass of a substance to mole. (ii) Unit of concentration and hence define the term concentration

How will you prepare a $0.05 \mathrm{M}$ solution of $\mathrm{H}_{2} \mathrm{SO}_{4}$

Define (a) the mole (b) molar mass (c) (d) standard solution.

How does the mole relate to mass?

How many moles are in $36 \mathrm{~g}$ of water?

What is the benefit of the mole to the chemist?

Do a glossary of important words you came across during the lesson.

Write a balanced equation of the reaction between potassium hydroxide and tetraoxosulphate VI acid (sulphuric acid); show ratio of reactants to products in the balanced equation and the actual number of moles of reactants to products. 


\section{Data Analysis}

Results of mean achievement scores of male and female students for the experimental group taught through The Learning Cycle and the control group taught by Traditional Approaches are shown in Table 1 below:

Table 1. Means and standard deviation of students' scores in post-treatment (by treatment by gender)

\begin{tabular}{|l|l|l|l|l|}
\hline & \multicolumn{4}{|l|}{ GENDER } \\
\hline \multirow{4}{*}{ Treatment } & & M & F & Overall \\
\hline & Mean & 31.42 & 30.06 & 30.74 \\
\cline { 2 - 5 } & SD & 13.43 & 12.49 & 13.46 \\
\cline { 2 - 5 } & $\mathrm{N}$ & 103 & 112 & 215 \\
\hline \multirow{3}{*}{ Control } & Mean & 23.46 & 24.16 & 23.81 \\
\cline { 2 - 5 } & SD & 13.31 & 11.82 & 12.56 \\
\cline { 2 - 5 } & $\mathrm{N}$ & 101 & 114 & 215 \\
\hline Overall & $\mathrm{N}$ & 204 & 226 & 430 \\
\hline
\end{tabular}

Overall result of mean achievement scores for the experimental group taught through the learning cycle and control group taught by traditional approach as shown in Table 1 reveal that the experimental group had a higher mean score of 30.74 as against 23.81 for the control group. The table and the bar chart below also show that the male students in the experimental group appeared to have higher mean score than the female students, that is, 31.42 and 30.06 respectively. The male and female students in the experimental group had a higher mean score than male and female students in the control group.

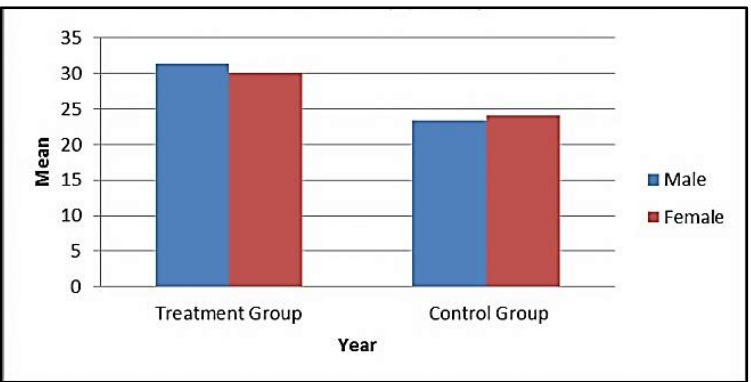

Figure 5. Mean of students' scores in post-treatment (by treatment by gender)

Results of pretest posttest mean achievement scores for male and female students in chemistry tests for the experimental group are shown in the Table 2 below.
Table 2. Overall means for boys and girls in experimental group in pretest and post-test

\begin{tabular}{|l|l|l|l|l|}
\hline \multirow{3}{*}{ Pretest } & \multicolumn{3}{|l|}{ GENDER } & \\
\hline \multirow{4}{*}{ Post test } & Mean & 22.91 & 22.20 & 22.55 \\
\cline { 2 - 5 } & SD & 15.59 & 17.13 & 16.36 \\
\cline { 2 - 5 } & N & 103 & 112 & 215 \\
\hline \multirow{3}{*}{ Overall } & Mean & 31.42 & 30.06 & 30.74 \\
\hline & SD & 13.42 & 12.49 & 12.95 \\
\hline & M & 103 & 112 & 215 \\
\hline & Sean & 27.16 & 26.13 & \\
\hline
\end{tabular}

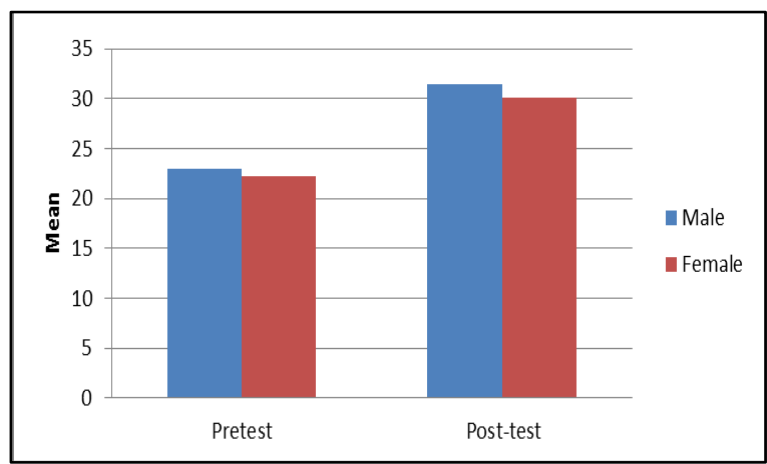

Figure 6. Overall means for boys and girls in experimental group in pretest and posttest

To examine the effect of gender on mean achievement scores of students in Chemistry tests, pretest - post-test results show that before treatment, male students scored 22.91 while female students scored 22.20. After treatment, the post-test mean scores showed that both male and female students improved with the mean score of male students increasing from 22.91 to 31.42 while that of the female increased from 22.20 to 30.06 . Overall mean scores for male and female students were 27.16 and 26.13 respectively. The male students appeared to score higher than the female students in the chemistry tests.

Results of Analysis of variance carried out to determine the statistical variance of post-test scores for control and experimental groups are shown in Table 5 below: 
Table 3. The ANOVA for post-test for the two groups

\begin{tabular}{|l|l|l|l|l|l|}
\hline $\begin{array}{l}\text { Source of } \\
\text { difference }\end{array}$ & $\begin{array}{l}\text { Sum of } \\
\text { squares }\end{array}$ & df & $\begin{array}{l}\text { Mean } \\
\text { Square }\end{array}$ & F & Sig \\
\hline $\begin{array}{l}\text { Between } \\
\text { Groups }\end{array}$ & 3383.283 & 1 & 3383.283 & 18.80 & 0.00 \\
\hline $\begin{array}{l}\text { Within } \\
\text { Groups }\end{array}$ & 73063.531 & 438 & 179.959 & & \\
\hline Total & 76446.814 & 429 & & & \\
\hline
\end{tabular}

The mean difference between the control and the experimental groups is statistically significant at 0.00 level. The hypothesis of no significant difference between the mean scores for control and experimental group is therefore rejected at 0.05 level. Thus, the results as shown in Table 1 (mean score of 30.74 for experimental group and 23.81 for control group) are confirmed by ANOVA as significant; that is, the experimental group had a higher mean score than the control group.

To determine the level of difference in mean scores for boys and the girls in the experimental group, independent t-test was carried out. The results are shown in Table 4 below:

Table 4. Independent t-test for boys and girls in experimental group pre-test

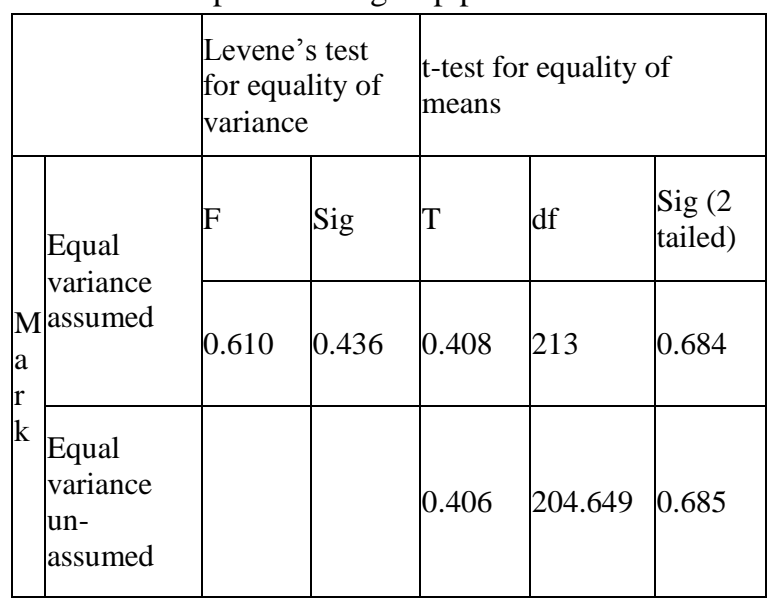

At 0.684 level, gender as the main effect is not significant, since this level is higher than 0.05; thus the level of difference in pretest scores for boys and girls (22.91 and 22.20) was not statistically significant.
Independent t-test for boys and girls in posttest experimental group revealed results as shown in Table 5:

Table 5. Independent t-test for boys and girls in the experimental group post-test

\begin{tabular}{|l|l|l|l|l|l|}
\hline \multicolumn{2}{|l|}{} & \multicolumn{2}{|l|}{$\begin{array}{l}\text { Levene's } \\
\text { test for } \\
\text { equality of } \\
\text { variance }\end{array}$} & \multicolumn{4}{|l|}{ t-test for equality of } \\
means
\end{tabular}

The results showed that 2- detailed independent $\mathrm{t}$ - test of post test scores for boys and girls in the experimental group is not significant because 0.436 is higher than 0.05 . That is, the null hypothesis of no significant gender effect is not rejected. Therefore, there is no significant combined effect of teaching method and gender on students' achievement scores in the chemistry tests.

\section{Discussion}

The results of this study provided an empirical evidence of the efficacy of the learning cycle in the teaching of chemistry. The experimental group produced higher mean achievement scores than the control group taught, the same content/concepts in chemistry using the traditional methods. The findings of this study is in consonance with Ergin et al. who found that the $5 \mathrm{E}$ learning cycle impact significantly on students' retention, achievement and understanding [6].

The importance of deeper learning as a means of developing learners' capacity to apply knowledge gained during the learning process to problem solving was reflected in this study since the students taught through the learning cycle demonstrated their understanding of the concepts during the evaluation phase. Students active participation, their interaction in groups and the 
teacher's role as provider of thought provoking questions might have enhanced students' achievement gains in the chemistry tests as established by Moyer et al [11]. The result of this study showed that there is no significant difference in achievement between male and female students in the experimental group taught selected topics in chemistry using the learning cycle. This means that boys and girls benefited from the learning cycle. Thus, achievement in chemistry is not in any way a function of sex.

The findings of this study have implications for chemistry and science teachers in Kenya secondary schools. The persistent failure of students in chemistry could be arrested if teachers were better equipped with inquiry skills and effective strategies such as the learning cycle. Teachers should desist from being agents of knowledge transmission and learn to transfer ownership of learning to their students. Classroom lessons should be organized to include concrete explorations and inquiry to elicit learners' potential to think creatively, to participate actively, creatively and reflectively. Social interaction among students and with teachers should also be encouraged in teaching and learning.

The SMASSE project in process should include professional development of teachers' on inquiry approaches in the science classrooms. Teachers are by this study urged to minimize the use of talk and chalk method in teaching science subjects and to adopt such methods as the learning cycle in several innovative ways to motivate students' interest and conceptual understanding in chemistry.

\section{Conclusion}

The study sought to examine the efficacy of the learning cycle on secondary school students' achievement in chemistry. Evidence from the analysis of Kenya Certificate for Secondary Education (KCSE) results for the past decade showed that students' performance in science subjects has been low, chemistry being the poorest. Concern by major stakeholders attracted studies to find out ways that could enhance performance since traditional approaches which were commonly used for teaching chemistry did not engender meaningful learning and conceptual understanding. This study was therefore used to ascertain how the learning cycle will impact on performance of form II chemistry students in Bureti district in Kenya. Results from the study showed that meaningful strategy which encompasses inquiry approaches, cooperative learning in groups and critical thinking can significantly influence students' learning outcomes.

The learning cycle which was developed from Paget's theory many years ago is still an effective teaching strategy and can be embraced in many novel ways by teachers in chemistry classrooms. It is important to note that a very important aspect of the procedure is the transfer of ownership of learning to the students whiles the teacher functions as a facilitator. The teacher builds from students' prior knowledge and encourages them to construct their own views of the chemistry concepts. This study revealed that the learning cycle favored both boys and girls, giving credence to the learning cycle as a gender sensitive approach.

Finally, since the experimental group performed better than the control group in this study, perhaps the desired result in Kenya Secondary Certificate Education may ensue if teachers improved on their pedagogical skills by creatively adopting the learning cycle. By implication, more candidates will enroll in Science and Medical Faculties in the universities which will in turn boost the human capacity in science related fields needed for national development

\section{References}

[1] Atherton, J.S. (2011). Learning and teaching: assimilation and accommodation. Retrieved on-line 2 January, $2013 \mathrm{http}: / / \mathrm{www}$. learningandteaching, info/learning/assimilation

[2] Ausubel, D.P. (2000). The acquisition and retention of knowledge: a cognitive view. Kluwer Academic Publishers

[3] Bybee, R. W. (2009). The BSCS 5E instructional model and 21st century skills: A commissioned paper prepared for a workshop on exploring the intersection of science education and the development of 21 st century skills.

[4] Bybee, R. W., Taylor, J.A., Gardner, A., Scotter, P. V., Powell, J. C., Westbrook, A., \& Landes, N. (2006a, July) The BSCS 5E instructional model: Origins, effectiveness, and applications.

[5] Chepkemoi, C.L. (2011). A comparative study of factors that influence the academic achievement of students in boarding and day secondary schools 
of Kericho District, Kenya. Master's thesis. Kenyatta University, Kenya.

[6] Ergin, I, Kanli, U \& Unsal, Y. (2008). An example for the effect of the $5 \mathrm{E}$ model on the academic success and attitude levels of students': "Inclined projectile motion." Journal of Turkish Science Education, 5, 47-59.

[7] Eze, C. C. (2010). Repositioning chemistry education in Nigerian Colleges of Education for Economic empowerment. In Nskak-Abasi Udofia. $51^{\text {st }}$ Annual Conference proceedings Science Teachers Association of Nigeria (STAN). 287-292

[8] Fosnot, C.T. (1989). Enquiring teachers, inquiring learners. New York: Teachers College Journal of the Science Teachers' Association of Nigeria 43, (1\&2), 16-22.

[9] Kenya National Examination Council (KNEC), Kenya Certificate for Secondary Education (2005 2010)

[10] Lovat, T. (2003). The role of the 'teacher' coming of age. Melbourne: Australian Council of Deans.

[11] Moyer, R.H., Hackett, J.K. \& Everett, S.A. (2007). Teaching science as investigations: Modeling inquiry through learning cycle lessons. Upper Saddle River, New Jersey: Pearson Prentice Hall.

[12] Pellegrine J. W. \& Hilton, M. L.(2012). Education for life and work: developing transferable Knowledge and skills in the $21^{\text {st }}$ century. National Research Council, Hewlett Foundation

[13] Peterson, P., E. Fennema \& Carpenter, T. (1998). Using knowledge of how students think about mathematics. Educational leadership. 46.42 $-46$

[14] Piaget, J. (1964). Part 1: Cognitive development in children: Piaget development and learning. Journal of Research in Science Teaching. $2,176-186$

[15] Pinker, (2003). "The Blank State: Modem Denial of Human Nature ". Viking: Published by penguin group. review of the Research

[16] Sudi, Y.M. (2012). An investigation of the probable causes of poor performance in the Kenya
Certificate of Secondary Education (KCSE) in Matuga Division, Kwale District, Coast Province. Unpublished M.Ed. thesis. Kenyatta University.

[17] Udoh, O. A. (2008). An analysis of classroom interaction of senior secondary school chemistry teachers in Ikot Ekpene Local Government Area of Akwa Ibom State Nigeria. Journal of the Science Teachers Association of Nigeria, 43(1 \& 2), 16-22.

[18] Vighnarajah, L., Luan, W. \&, K. Abubakar (2008). The shift in the role of teachers in the learning process. European Journal of Social Sciences. 7(2). 33-4

[19] Warburton, K. (2003). Deep learning and education for sustainability. International Journal of sustainability in higher education. 4 (10), 44-56. 